\title{
Correction to: Deep-Sea Organisms Tracking Using Dehazing and Deep Learning
}

\author{
Huimin $\mathrm{Lu}^{1} \cdot$ Tomoki Uemura $^{1} \cdot$ Dong Wang ${ }^{2} \cdot$ Jihua $\mathrm{Zhu}^{3} \cdot$ Zi Huang $^{4} \cdot$ Hyoungseop Kim ${ }^{1}$
}

Published online: 7 July 2020

(C) Springer Science+Business Media, LLC, part of Springer Nature 2020

\section{Correction to: Mobile Networks and Applications (2020) 25:1008-1015 \\ https://doi.org/10.1007/s11036-018-1117-9}

The original version of this article unfortunately contained a mistake in the Affiliation section. The captured affiliation of author "Hyoungseop Kim" was incorrect. It should be "Kyushu Institute of Technology" instead of "Dalian University of Technology".

The authorgroup section is now updated to reflect his correct affiliation designation.

Publisher's note Springer Nature remains neutral with regard to jurisdictional claims in published maps and institutional affiliations.

The online version of the original article can be found at https://doi.org/ 10.1007/s11036-018-1117-9

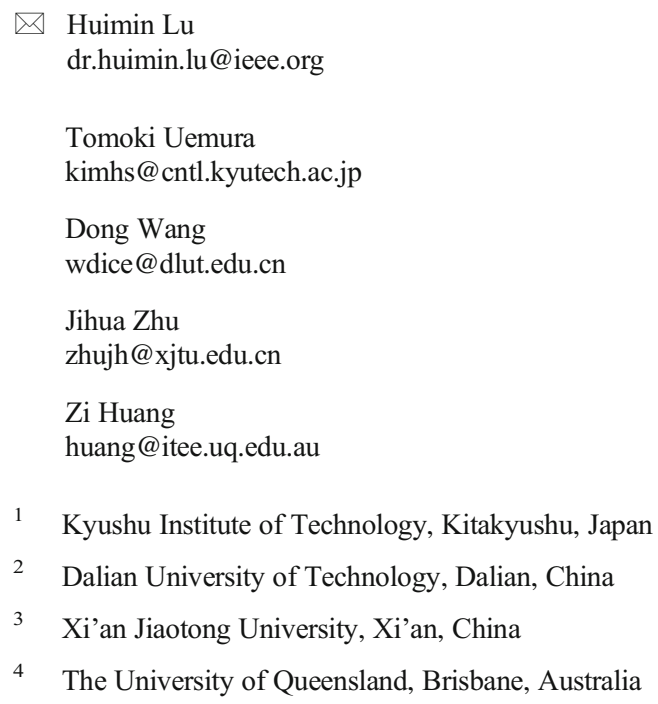

4 The University of Queensland, Brisbane, Australia 